\title{
An Empirical Study of BB Network Teaching Platform in College English Teaching
}

\author{
Dongliang $\mathrm{Wu}$ \\ Minnan Science and Technology Institute, Fujian Normal University, Nan'an, \\ Quanzhou,Fujian,362332, China \\ 23618904@qq.com
}

\begin{abstract}
At present, the research on the curriculum management platform is mainly focused on the development and application of technology. This research uses the method of case study to analyze the application of BB network teaching platform in College English teaching. At first, the author introduces the application of information technology in teaching, and analyzes the curriculum management platform, functional modules and the overall understanding of the university teaching, and thus the formation of curriculum management platform. BB platform cannot be limited by time and space, changing the traditional way of learning. In conclusion, $B B$ network learning platform can effectively improve the efficiency of English teaching and improve students' interest in English learning.
\end{abstract}

Keywords: BB Network platform, Online courses, English teaching, Teaching effect

\section{Introduction}

With the birth of the computer technology, the teaching method and the teaching mode based on the computer technology have been explored and carried out, which has promoted the process of the school education reform [1]. After the Second World War, the modern school education, to a certain extent, is based on the development and progress of the new educational method based on the computer platform. From this point of view, it is very necessary to study and analyze the support of information technology to college teaching, student learning and teaching management, which is of great practical value. BB network teaching platform developed by the United States Blackboard company, at present, there are many universities and educational institutions in the world are using the product, including the famous Harvard University [2-3], Stanford University, etc., BB network teaching platform to the curriculum as the center, including curriculum content, curriculum tools, curriculum options, testing and evaluation management and user management module. It uses the structure of the folder and the sub files for each module, the level is clear, clear, easy to operate and management of teaching [4]. BB network teaching platform set text, sound, images in one, and has the function of interaction between teachers and students and students, greatly enriched the form of students learning. In addition, it is a powerful test management function, so that it is convenient for teachers to monitor students' learning process and evaluate the process.

The traditional English Listening Teaching under the theory of behaviorism teaching is usually carried out in the listening classroom, the teacher is the center of teaching activities, teaching activities and control of the whole process, teachers provide students according to the listening material, in accordance with the requirements of teachers and provide the method and steps of passive listening task completed, many students in listening in the process of being passive [5-6], negative state, hearing effect. The construction of multimedia teaching mode under the guidance of educational theory can satisfy the different requirements of the different learning students set their own learning 
steps to complete the listening task, but this "autonomous" learning mode, some students can only complete their task of interest, and should strengthen the training of the content often cannot give enough attention, resulting in poor teaching effect and low efficiency results [7]. In order to improve the teaching effect, to avoid the disadvantages of the traditional teaching mode, reflect the personalized learning and teaching, effective management and monitoring of students' learning, blended learning mode came into being, and gradually become a new mode of learning is widely accepted by educators [8]. The effective combination of hybrid learning model emphasizes the traditional teaching mode to teach as the center of the advantages and learning centered teaching mode of multimedia advantages, to achieve a while emphasizing the teaching purpose and achieve the best teaching effect and achieve the hybrid using a variety of teaching methods.

\section{BB Network Teaching Platform}

As the world's largest provider of network teaching platform, network teaching platform is a set of voice, image and text in one, a kind of teaching mode teaching platform is committed to strengthening the virtual learning environment, classroom teaching and network teaching platform, network teaching platform and interactive. In the process of resource management, centralized online exchange BB platform, assessment and management, system management function module, breaking the traditional teaching in time and space, and the optimization of curriculum resources, more fully reflects the effective communication and interaction between teachers and students [9]. In the teaching mode, the teacher is no longer the spread of knowledge; it is the organizer and participant of the teaching process. Under the guidance of teachers and organizations, students to explore, cooperation and communication as the main form, get a lot of knowledge, so as to establish a set of lifelong development of the learning system.

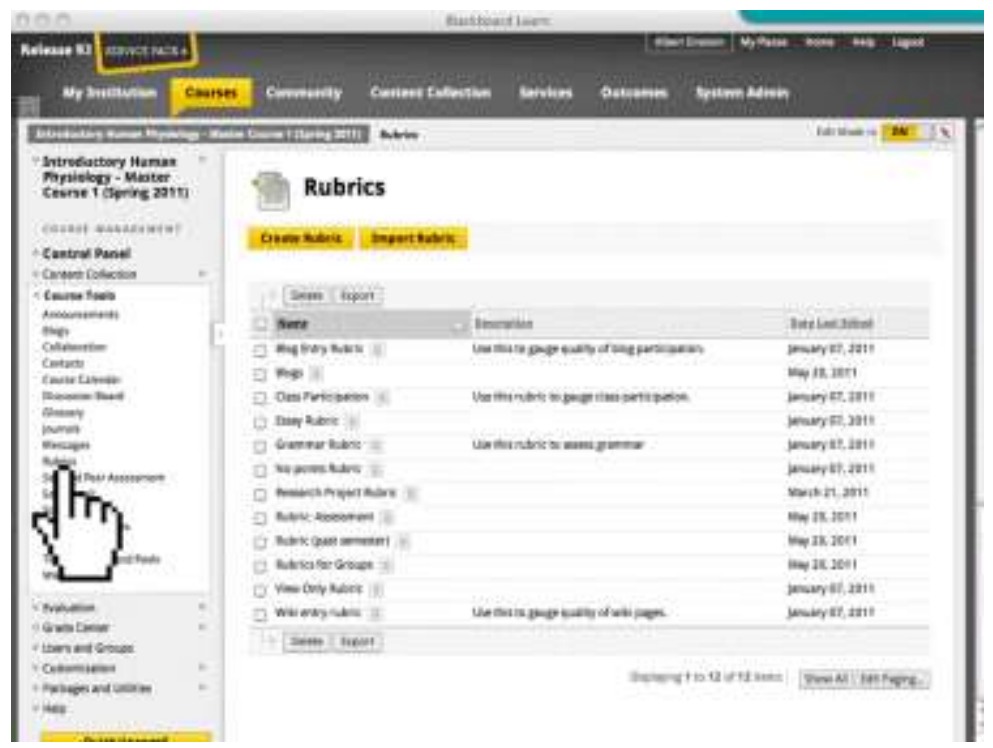

Figure 1. BB Network Teaching Platform

And the core function of BB platform is very powerful, so that teachers can create content, curriculum management, effectively generate work, strengthen cooperation and exchange and evaluation, to help enterprises achieve important objectives related to teaching. Since 2003, more than and 200 universities and educational institutions select the "BB" platform. We buy the use of the BB network teaching platform in 2007 began to go to school. At present, there are 187 English listening courses. 2008 create a formal network course. Based on the traditional teaching method, based on the BB platform, set up the network curriculum, curriculum information, curriculum documents, external links, 
operation, mainly for discussion, classroom teaching and extracurricular learning organically, make learning easier to learn, enrich the forms of learning, the effect is more prominent, can greatly stimulate students' learning motivation. At the same time, the opening of the network courses to a large extent make up for the traditional teaching of small defects in the teaching of science and information, so that students from the classroom to the outside of the classroom, in order to ensure adequate language input. As the teaching content, teaching platform BB traditional operation and communication network test, to obtain new features, expanding teaching methods (especially the feedback information, real-time, personalized teachers) teaching, adjust teaching methods, fully mobilize the enthusiasm of students is very favorable.

Table 1. BB Teaching Platform Framework

\begin{tabular}{|c|c|c|c|}
\hline \multicolumn{4}{|c|}{ A comprehensive framework for the function of online teaching platform } \\
\hline \multirow[b]{2}{*}{$\begin{array}{c}\text { Function of } \\
\text { curriculum design }\end{array}$} & \multirow[b]{2}{*}{$\begin{array}{l}\text { Communication } \\
\text { cooperation function }\end{array}$} & \multicolumn{2}{|c|}{ management function } \\
\hline & & $\begin{array}{l}\text { Curriculum } \\
\text { management } \\
\text { function }\end{array}$ & $\begin{array}{l}\text { Administrative } \\
\text { function }\end{array}$ \\
\hline 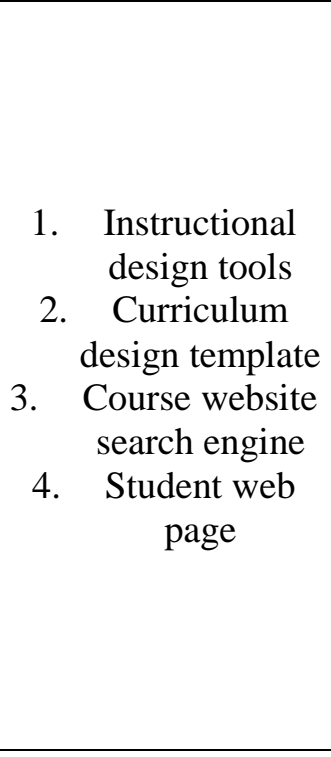 & $\begin{array}{c}\text { 1. } \\
\text { BBS discussion } \\
\text { 2. } \\
\text { anternal e-mail } \\
\text { 3. chat online } \\
\text { 4. Audio visual } \\
\text { conference } \\
\text { 5. File sharing } \\
\text { 6. Working group } \\
\text { 7. Electronic } \\
\text { whiteboard }\end{array}$ & 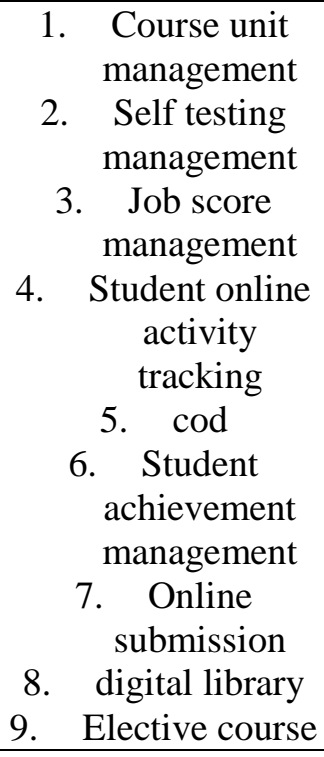 & $\begin{array}{c}\text { 1. Secure login } \\
\text { 2. } \\
\begin{array}{c}\text { Technical } \\
\text { support }\end{array}\end{array}$ \\
\hline
\end{tabular}

\section{BB Platform to Evaluate the Effective use of the University}

The function module design of BB platform is the main line, communication and evaluation. It can support different types of learning models, such as autonomous learning, cooperative learning and interactive learning platform. BB learning is to strengthen and supplement the traditional classroom teaching, the virtual learning environment provides a better, can maximize the sharing of teaching resources and interactive opportunities. 


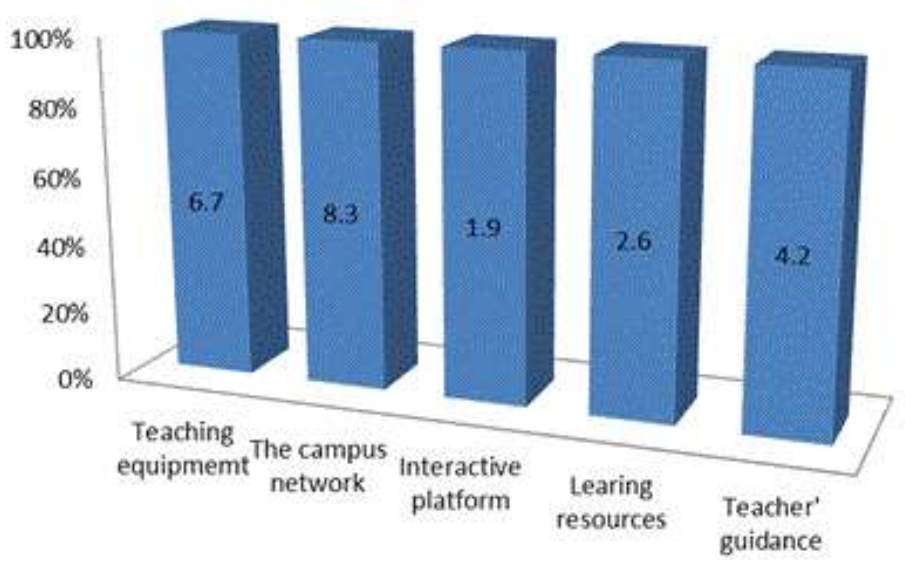

Figure 2. Proportion of Equipment

\subsection{Enrich the Teaching Content}

With the development of computer science and technology, the further development of network and multimedia technology is more and more colorful. In the Taishan plain BB can upload learning materials, a series of text and background, the author's writing background and problems, so you can watch the video and audio data and other written materials are complete, through the network platform. Students can also upload a platform to share with teachers and other students, help to accumulate more information, in the teaching process of teachers' teaching process and students' information of one-way transmission of information.

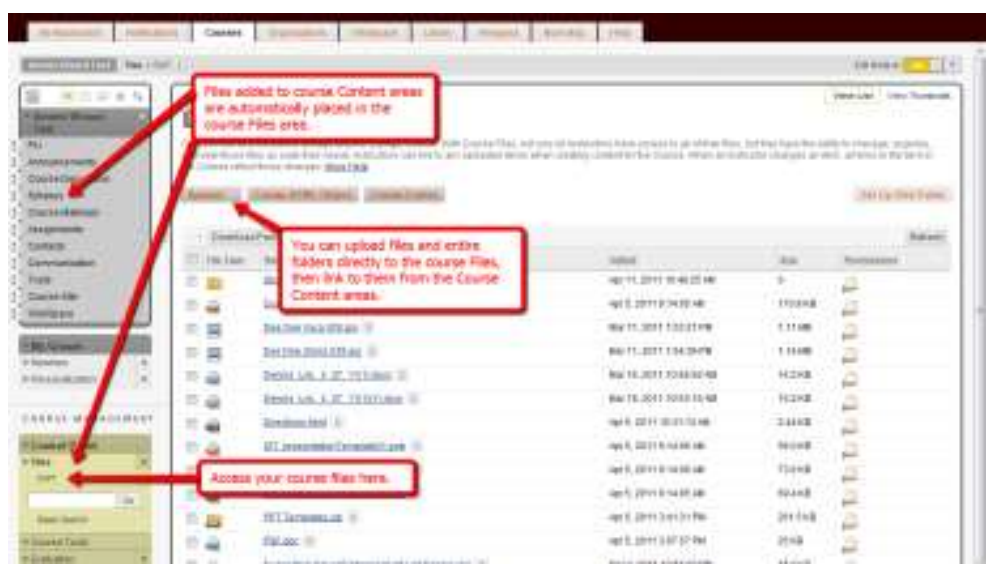

Figure 3. BB Network Teaching Content

\subsection{Broaden the Knowledge Channel}

Library, information room and network is a huge information base. In the face of such a wealth of information resources, how to access and use valuable information becomes a learning ability. According to different teaching content and research topics, we encourage students to use a variety of resources to find relevant information, after screening, to complete the data uploaded to the BB platform for all teachers and students to share. In the multitude of information resources, the students will be exposed to the process of transcendence, combined with some information; collecting all kinds of information and effective screening, can not only stimulate students' knowledge, enrich their knowledge structure, but also can learn and exercise logical thinking ability and 
comprehensive ability. Lay the foundation for the cultivation of students' graduation thesis.

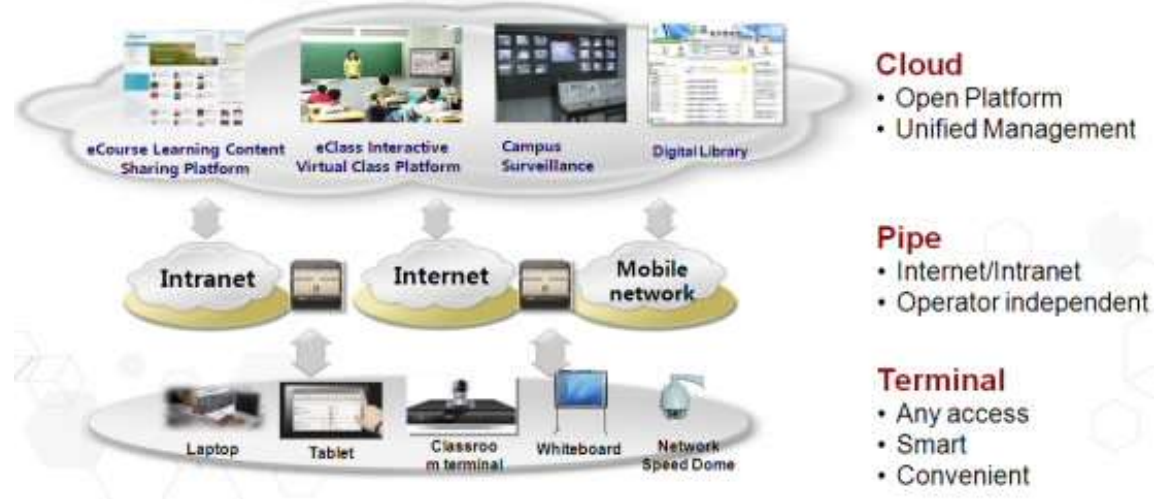

Figure 4. Online Learning Way

\subsection{Autonomous Learning Ability}

In the teaching mode, teachers from the traditional "knowledge" to the leadership, the coordinator and the answer to the transition, the main task is to help and guide students to find the key and research topics. Students are no longer passive acceptance of knowledge, only waiting for the teacher to feed, but the initiative to search for relevant information, and in the BB platform to communicate with teachers and other students. Every student has the responsibility and obligation to contribute their ideas and opinions in the communication with others. According to their actual needs, the use of a variety of resources to tap the knowledge of the process, is the process of self construction of students, this is a cycle of reflection, interaction process. This kind of active participation process further stimulates the student's study initiative, has played an important role in the teaching. Improving autonomous learning ability is helpful to the cultivation of students' autonomous learning and lifelong learning habits and attitudes.

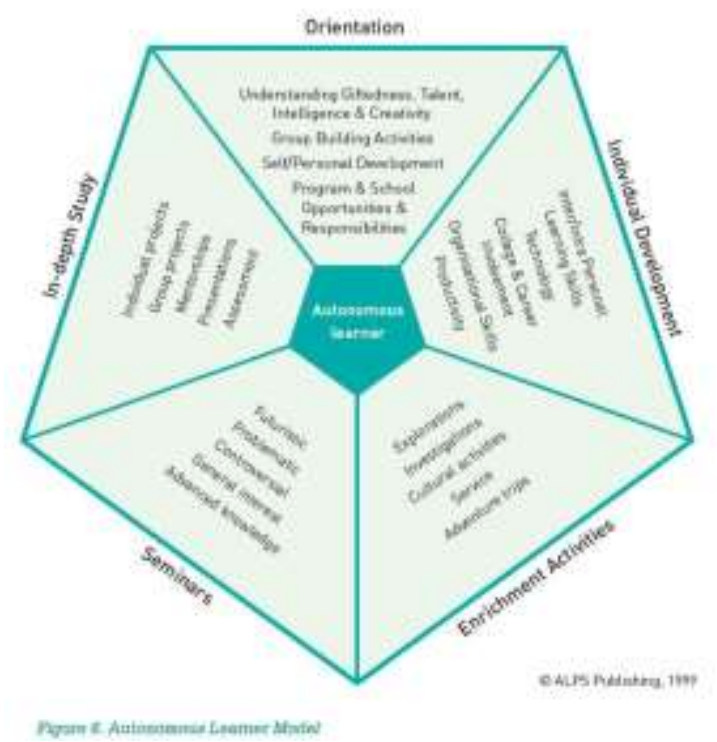

Figure 5. Autonomous Learning Ability

Table 2. Student Achievement Comparison

\begin{tabular}{|c|c|c|c|c|c|c|}
\hline class & Mean & Std.Deviation & Std.error & $\mathrm{t}$ & $\mathrm{df}$ & $\mathrm{p}$ \\
\hline
\end{tabular}




\begin{tabular}{|c|c|c|c|c|c|c|}
\hline $\begin{array}{c}\text { Experimental } \\
\text { class }\end{array}$ & 62.45 & 5.3987 & 0.4563 & 1.678 & 132 & 0.789 \\
\hline Control class & 64.01 & 6.4655 & 0.9678 & & & \\
\hline
\end{tabular}

\subsection{Cultivating Students' Thinking Ability}

Influenced by the Chinese culture and the traditional teaching mode, few students have a critical understanding of knowledge, and there is no doubt about the authority of teachers. Most teachers in the actual teaching process is also used to maintain their authority image, do not take the initiative to encourage students to criticize the teaching content of the point of view. If things go on like this, students are gradually losing their ability to think independently, not more.

Have the spirit of exploration, take the initiative to find the problem, solve the problem. In the BB platform, teachers encourage students to comment on the subject and text content, as well as the author's point of view. In this process of interaction, students will hear different opinions, will be on their own point of view, it will take the initiative to find more information to support their views or refute the views of others. In this cognitive conflict, students will think of their own knowledge, and then added, and then set up. Lively discussion of students, not only exercise their ability to use the language flexibly, but also cultivate their own logical thinking ability and independent thinking ability. These abilities will help students to learn other professional courses, but also help them to enter the community after the independent study and work.

Table 3. Student Achievement Comparison

\begin{tabular}{|c|l|l|l|l|l|l|}
\hline class & Mean & Std.Deviation & Std.error & t & df & $\mathrm{p}$ \\
\hline $\begin{array}{c}\text { Experimental } \\
\text { class }\end{array}$ & 78.45 & 8.3789 & 0.8790 & 2.678 & 132 & 0.000 \\
\hline Control class & 68.65 & 10.4625 & 1.4364 & & & \\
\hline
\end{tabular}

\subsection{Construction of Evaluation System}

In the operation of the BB platform, testing and statistical system, can reflect the work completed and participate in student activities platform. In the teaching mode, we try to assess the knowledge of the traditional evaluation system is the core of formative evaluation, the evaluation system of examination ability, is focused on the evaluation of students' autonomous learning ability and consciousness is to improve and solve problems, improve the ability of independent thinking and no improvement. By tracking the performance of students in the BB platform, teachers can clearly see the indicators of these potential factors instead of the traditional teaching process that can be quantified. This new dynamic evaluation system has changed the traditional examination way more stringent, make students pay more attention to their learning process, and actively participate in the teaching process, more and more shows the main function, teaching evaluation, and often form a virtuous cycle. 


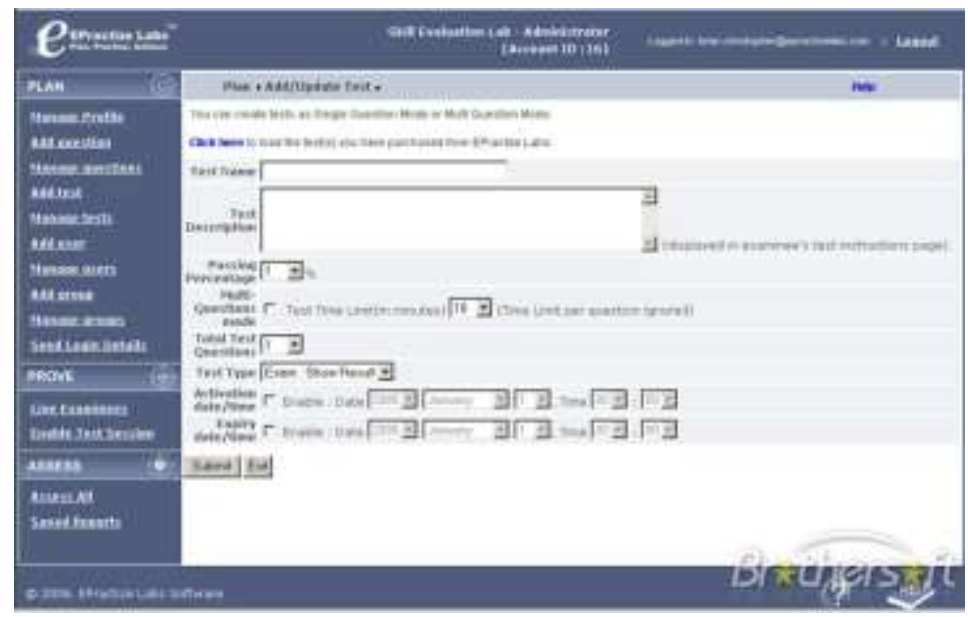

Figure 6. Online Course Test

\subsection{Strengthen Communication}

The use of BB platform provides convenient conditions for communication. In teaching and learning activities are no longer confined to the classroom, all the students will participate in the activities of the BB platform, according to their own ability and rhythm. Teachers can also participate in the discussion of the platform at any time, so that it can be a proper adjustment and control for each student.

Create a relatively equal opportunity to participate. In these aspects of interaction, each student can accord their own ability and demand, step by step to improve the understanding of knowledge, thus forming a positive construction process.

Constructivist teaching theory emphasizes the concept of "people oriented", which is based on the study of the teaching practice of high school English teaching and learning. Further implementation of the BB platform, the teacher is the leader, the student is the target browser, so that students explore and discover their own construction under the guidance of teachers, learning problems of critical thinking and their role". BB network teaching platform to assist senior high school English teaching process, teachers should recognize and respect the individual differences of students; each student as different individual learning, different in each part of the BB platform, different information, different views and opinions. The communication between teachers and students can improve the learning process of each participant.

\section{Suggestions for Improvement of BB Platform}

In the $\mathrm{BB}$ platform to run, need a lot of manpower, but the analysis in the $\mathrm{BB}$ platform, although the use of BB platform to strengthen to a certain extent, and the traditional classroom teaching, expanding the traditional classroom teaching space, but still did not play its biggest role. This part puts forward some suggestions on how to better use the BB platform to support classroom teaching, in order to improve the learning methods and learning effects. 


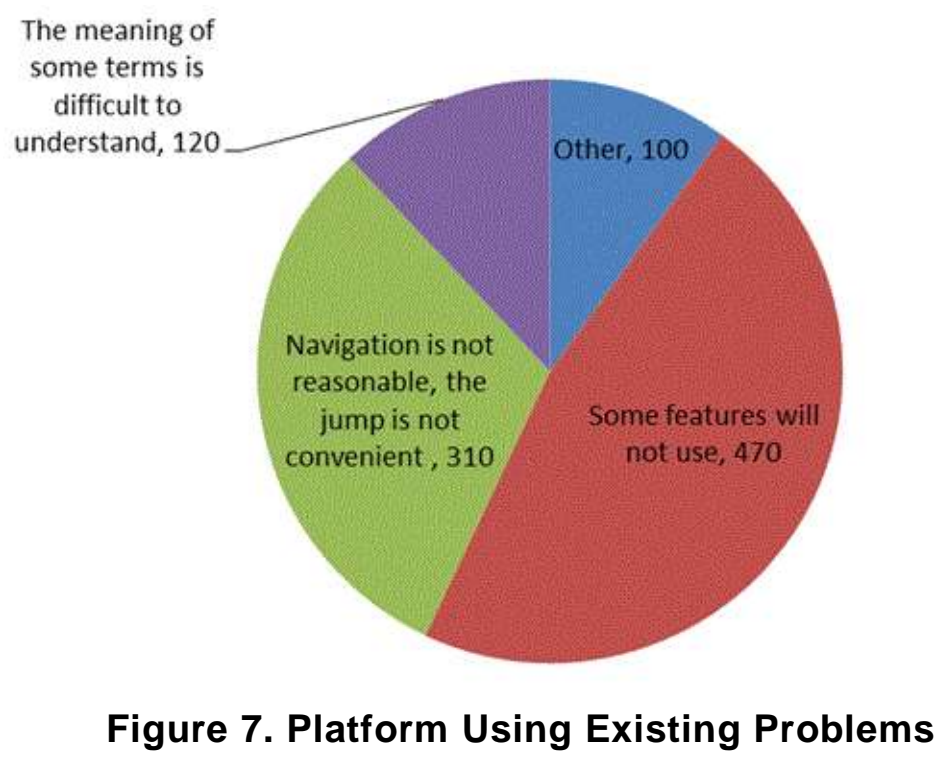

\subsection{Increase the Function and Development of the Platform}

Data analysis showed that the realization of the BB platform is the most important factor in the learning effect. The BB platform project, the vacancy rate is high, the teacher needs a single function, therefore, teachers should play a guiding role, and actively explore various functions using the BB platform, on the platform of the design of teaching activities, and demonstrates how to operate, guide students to use more features. Secondly, put forward specific requirements of the teacher, give the students more opportunities to use, a new thing is not familiar with the students, but with the increasing frequency of use, the students operate more smoothly, the learning effect will be better. Many students, in an interview with QQ, the campus network, because of the use of all his teachers and classmates, so they will use more frequently, teachers and students will be familiar with the function, but if you don't use it, not logged in, you don't know what resources.

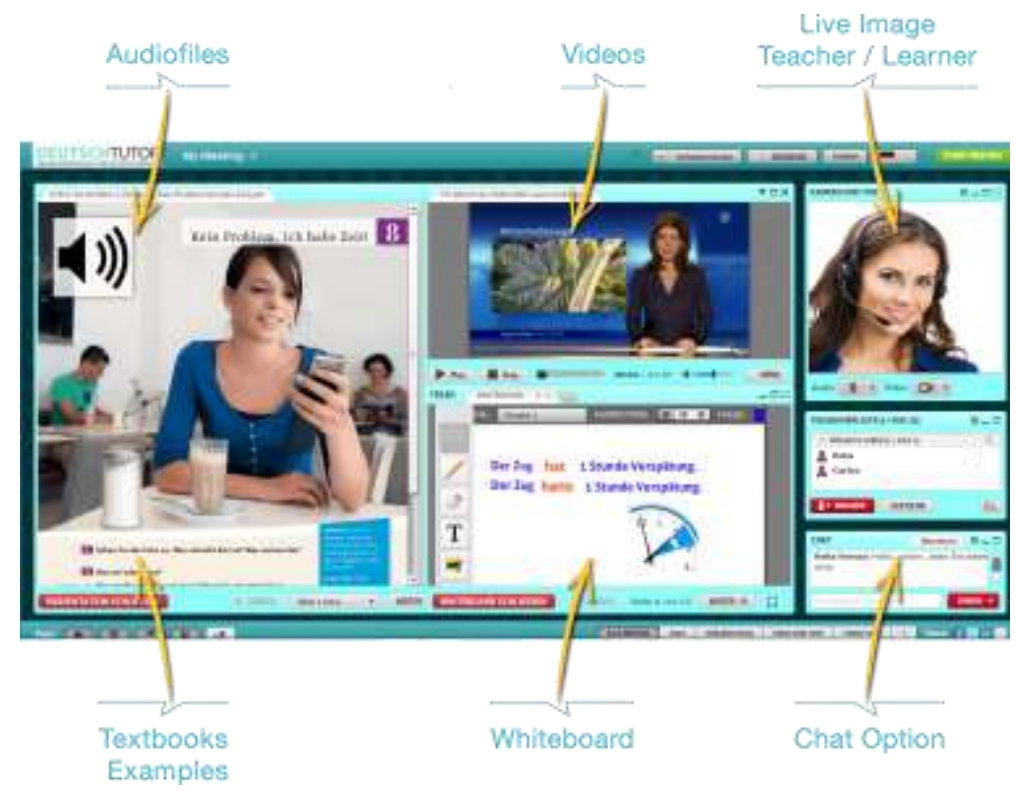

Figure 8. Network Platform Function

\subsection{Further Enrich the Platform of Teaching Resources}


Interactive information and teaching information in the $\mathrm{BB}$ platform is the main function of the factors influencing the learning effect, second, and the main function of the $\mathrm{BB}$ platform module is to combine. The following proposal is based on the existing BB platform:

1. Information release: Fully release the details of the information, as far as possible the complete curriculum information, curriculum notice, etc., are posted on the platform.

2. upload resources: First of all, upload courseware faster, some of the best data uploaded before class, is a good platform for students to preview; secondly, textbooks or teachers should not repeat, upload some more valuable resources, expand the range of resources, rich content, including some related courses and the expansion of resources, a part of the class resources, increase the breadth of knowledge, improve the resource types, such as websites, bibliography; thirdly, resource classification is clear, which is convenient for students to find the resources they need; teachers should update the resources, update the best communication platform by $\mathrm{BB}$ or other ways to inform Kazakhstan teacher education courses do not delete the courseware, because students sometimes forget to download courseware.

3. Participate in the discussion: The participation of teachers can stimulate students' enthusiasm; on teacher feedback, discussion board regularly given a reply and comment, not too long time to increase the interaction of students, for students to submit homework timely reply, otherwise there is no feedback, affecting the enthusiasm of the students, reduces the learning motivation and learning motivation.

4. line test: BB platform on this topic there is little or no test, I hope the teacher can increase the examination questions, provide answers and analysis, so that students can find their lack of learning, hope that the teacher can online Q \& A.

5. group activities: Multi design, organize group activities, students can establish a discussion group to study, organize group discussion, encourage students to discuss, develop the ability of cooperative learning.

\subsection{To Strengthen the Training and Supervision of the use of the Platform}

Data analysis showed that the use of the BB platform based on the general features of the skilled operation affected the use of the platform, while the effective platform for the operation and training of students from the school to provide practical operational capabilities.

In the traditional classroom teaching, students should change new ideas, they should first see positive results, can let the student through some successful cases, the BB will have great influence on their learning. School administrators should change the curriculum, training, provide technical training and technology is a separate activity, if there is no objective environment, will soon be forgotten, so when the basic knowledge, teachers and students, they need more technology to combine the teaching environment, teachers and students must technology is often combined with the practice, so I think it is necessary, the formation of teachers and students using a set of regular exchanges of experience on the BB platform, that is to say, in addition to providing technical school, can let the teachers and students have enough time to learn and help each other.

\section{Conclusions}

This article through to the university English teaching BB network teaching platform application present situation and the effect launches the research. BB teaching platform, promote English teaching, is a powerful complement to classroom teaching, especially helps students' autonomous learning and cooperative learning; on the other hand, the survey also found that, in order to adapt to the new teaching mode, improve the theory and network teaching ability of software and hardware facilities of the school teachers' 
level needs to be to improve, these are in the College English teaching reform direction of our future work.

\section{Acknowledgments}

The work of this paper is supported by Fujian Province Education Department for Middle-aged and Young (Grant No.JAS160814).

\section{References}

[1] L. Mengtao and W. Min, "Using multimedia technology to promote college English listening and speaking teaching", foreign language circle, vol. 5, (2002), pp. 2-9.

[2] J. Fan, "An investigation report on the attitudes and effects of college students on Computer Assisted Foreign Language School", Foreign language teaching, vol. 6, (2004), pp. 69-73.

[3] H. Fang, "A new model of computer network aided English teaching and learning", Language teaching, , vol. 10, (2007), pp. 43-48.

[4] J. Bruner, "The process of education", Harvard University Press, (1960), pp. 51-60.

[5] D. P. Ausubel and D. Novak, "Educational Psychology", A Cognitive View, (1978), pp.70-72

[6] G. G. Roberson, S. K. Card and J. D. Mackinlay, "The cognitive co -processor for interactive user interfaces", In Proceedings of UIS'89, "ACM Symposiom on use interface and software and technology", New York, USA: ACM Press, (1989), pp. 81-89

[7] C. Chen, "Searching for intellectual turning points: Progressive knowledge domain visualization", Journal of PNAS, vol. 101, no. 1, (2004), pp. 5303 -5310.

[8] C. Chen "CiteSpace II : Detecting and visualizing emerging trends and transient patterns in scientific literature", Journal of the American Society for Information Science and Technology, vol. 57, no, 3, (2006), pp. 359-377.

[9] C. Chen, Z. Hu, S. Liu and H. Tseng, "Emerging trends in regenerative medicine: a scientometric analysis in CiteSpace", Journal of Expert Opinion on Biological Therapy, vol. 12, no. 5, (2012), pp. 593 -608 . 